\title{
Effect of a unilateral or bilateral twin embryo distribution on twinning and embryo survival rate in the cow
}

\author{
J. M. Sreenan and M. G. Diskin \\ Agriculture and Food Development Authority, Belclare, Tuam, Co. Galway, Ireland
}

\begin{abstract}
Summary. Uni- and bilateral twin embryo distributions were effected by the transfer of one embryo on Day 7 to the ipsi- or contralateral uterine horn of previously inseminated heifers (123, Exp. 1) or cows (95, Exp. 2). The embryo transfers were surgical in Exp. 1 and non-surgical in Exp. 2. Transferred and native embryos were distinguished by breed. Embryo survival rate was measured in a proportion $(\mathrm{N}=40)$ of the heifers at Day 53 of gestation and in the remainder of the heifers and all of the cows at term. In the heifers (Exp. 1) overall pregnancy rates of $76 \%$ and $75 \%$ were recorded after uniand bilateral twin embryo distributions respectively. Twinning rates of $55 \%$ and $60 \%$ at Day 53 of gestation and $60 \%$ and $60 \%$ at term were recorded for uni- and bilateral distributions respectively. In the cows (Exp. 2) calving rates of $61 \%$ and $63 \%$ and twinning rates of $33 \%$ and $38 \%$ were recorded following uni- and bilateral twin embryo distributions respectively. When the data from both experiments were combined, overall embryo survival rates were similar for both twin embryo distributions although the ipsilateral transfer of an embryo reduced the survival rate of the native embryo. It is concluded that the confinement of two embryos in one uterine horn on or after Day 7 does not depress pregnancy, twinning or overall survival rate to term.
\end{abstract}

Keywords: embryo distribution; twinning; survival rates; cow

\section{Introduction}

Most published estimates of the frequency of natural twin births in the cow fall within a range of $1-5 \%$ depending mainly on breed, parity and environmental conditions (see reviews by Gordon et al., 1962; Scanlon et al., 1974; Morris, 1984). Increasing this frequency would be expected to increase the biological efficiency of the cow (Dickerson, 1983; Diskin \& Hickey, 1987).

Rowson et al. (1971) were first to show that ovulation rate and not uterine capacity is the main factor limiting twin-calving rate in the cow. This was later confirmed by many others (see review by Sreenan, 1977). Attempts to increase ovulation rate in the cow as a means of increasing twincalving rate include mild superovulation (Mauleon et al., 1978), genetic selection (Piper \& Bindon, 1979; Morris \& Day, 1986) and hormone immunization (Wise \& Schanbacher, 1983; Sreenan, 1984; Webb et al., 1984). These approaches, if successful in inducing a high proportion of twin ovulations, should result in the occurrence of unilateral twin ovulations in $50 \%$ of such cases. However, there are some reports showing a unilateral twin ovulation rate of $75 \%$ in twin-ovulating heifers (see review by Hanrahan, 1983). There are suggestions in the literature that unilateral twin ovulation results in a high rate of embryonic death and consequently a low twinning rate (Gordon et al., 1962; Rowson et al., 1971). Hanrahan (1983), reviewing the literature on embryo loss in cattle, calculated that the probability of embryo loss was increased by $22 \%$ for unilateral twin ovulations compared with bilateral or single ovulations, both of which had similar embryo survival rates. Unlike the sow or the ewe, transuterine migration of ova or embryos rarely occurs in the cow (Scanlon, 1972), and it has been postulated that the consequent overcrowding of two embryos 
within one uterine horn results in the death of one of the embryos in a high proportion of cases (Rowson et al., 1971). If this were the case, an increase in the proportion of cows with twin ovulations should not result in equal increases in twin-calving rates among animals with uni- and bilateral twin ovulation distributions.

In the studies reported here we have carried out either ipsilateral or contralateral embryo transfers to previously inseminated recipients to examine the effect of twin embryo distribution (unilateral $v s$ bilateral) on embryo and fetal survival through to term in primiparous heifers (Exp. 1) and mature cows (Exp. 2).

\section{Materials and Methods}

\section{Experiment 1}

Animals. A total of 123 sexually mature (20-24 months of age) Aberdeen Angus and Hereford cross heifers within a liveweight range of $370-440 \mathrm{~kg}$ were used as embryo recipients to determine the effect of twin embryo distribution on pregnancy, embryo survival, calving and twin-calving rates. The heifers were treated with short-term intravaginal progestagen-impregnated sponges to induce a synchronous oestrous response (Mulvehill \& Sreenan, 1978) and were checked for the occurrence of standing oestrus with the aid of a vasectomized bull. All heifers were artificially inseminated once during an observed standing oestrus and all inseminations were carried out by the same technician at $6-12 \mathrm{~h}$ after the heifers were first observed to stand. Frozen-thawed semen $\left(30 \times 10^{6}\right.$ spermatozoa per straw) from one Charolais bull of known high fertility (90-day non-return rate of $78.0 \%$ ) was used for each insemination.

Embryos. Embryos were collected following the induction of superovulation in donor heifers of a breed similar to that of the recipients. After the administration of PMSG (Folligon, Intervet Ltd, Milton Road, Cambridge, UK) and prostaglandin (Estrumate, Coopers Ltd, Berkhamsted, UK) during midcycle, the donor heifers were inseminated at the superovulation oestrus with frozen-thawed semen from one Simmental bull of known high fertility (90-day nonreturn rate of $83 \cdot 2 \%$ ). The use of different breed sires for the recipient and donor heifers allowed a distinction between the native and transfer calves at term. The superovulation and embryo recovery procedures were carried out as previously described (Sreenan \& Diskin, 1982).

Twin-embryo distribution. Unilateral and bilateral twin-embryo distributions were effected as follows. After insemination recipient heifers were randomly allotted to receive an embryo in the ipsilateral or contralateral uterine horn. The side of the corpus luteum was first determined by rectal palpation before transfer and was confirmed by direct observation of the ovary at the time of transfer. The embryo transfers were carried out in each case directly into the lumen of the uterine horn that had been exteriorized through the flank region. All transfers were carried out to synchronous recipients ( $0 \pm 1$ day) on Day 7 of the donor's cycle (Day $0=$ the day of oestrus) using freshly collected embryos. On a given day grade 1 embryos (morulae and blastocysts) collected from at least 3 donors were pooled and then randomly allotted to recipients. Embryo assessment was based on the criteria published by Elsden et al. (1978). Only heifers with a single corpus luteum were used as recipients. At the time of transfer about $15-18 \%$ of the recipients would not have a native embryo in the ipsilateral uterine horn because of a combination of fertilization failure and early embryonic deaths before Day 7 (see review by Sreenan \& Diskin, 1986). However, random allocation would distribute these equally between the ipsilateral and contralateral transfer groups. During the course of the transfers several recipient heifers were excluded because of poorly formed corpora lutea or difficulty during transfer. Excluding these animals, a total of 66 recipients received an embryo in the uterine horn ipsilateral and 57 in the uterine horn contralateral to the corpus luteum.

Measurement of embryo survival. All recipient heifers were pregnancy tested by rectal palpation between 45 and 50 days from the insemination. A random sample of those diagnosed as pregnant was then slaughtered from each of the ipsilateral $(\mathrm{N}=20)$ and contralateral $(\mathrm{N}=20)$ transfer groups at Day 53 of gestation to provide a measure of embryo survival rate up to the time of completion of implantation. Confirmation of a viable pregnancy and embryo survival at this time was based on the expected weight for age of each fetus, its fetal fluids and membranes (Sreenan \& Beehan, 1976). The remaining heifers diagnosed as pregnant $(\mathrm{N}=53)$ were held to full term but were pregnancy tested by palpation again on Day 150 from insemination. At calving, the number and breed type of each calf born were recorded for each recipient heifer.

\section{Experiment 2}

Animals. A total of 95 Hereford $\times$ Friesian second and later parity beef cows were used in this experiment to determine the effect of twin-embryo distribution on pregnancy, embryo survival and twinning rates in mature cows. Cows that had calved a minimum of 50 days previously had their oestrous cycles synchronized as described for Exp. 1 . Detection of standing oestrus, artificial insemination and embryo production were all carried out as described for Exp. 1. The embryo transfers in this experiment were carried out non-surgically using the procedure described by 
Sreenan \& Diskin (1982) but to ipsilateral or contralateral uterine horns as described for Exp. 1. Different breed sires were again used as in Exp. 1 to allow distinction between native and transfer calves at term. The cows were inseminated with semen from a Charolais bull (90-day non-return rate of $79 \cdot 7 \%$ ) and the donor heifers were inseminated with semen from a Simmental bull (90-day non-return rate, $75 \cdot 3 \%$ ).

Measurement of embryo survival. All recipient cows were pregnancy tested by rectal palpation at 50 days after insemination and those diagnosed as pregnant were kept and again pregnancy tested at 150 days after insemination. All cows diagnosed as pregnant at this second test were kept to term. At calving the number of breed types of calves born were recorded for each recipient cow.

\section{Statistical analysis}

Within each experiment, differences between proportions were tested by $\chi^{2}$ analysis and differences between means were tested by analysis of variance (Steel $\&$ Torrie, 1980).

\section{Results}

\section{Experiment 1}

In the heifers, pregnancy, twin-pregnancy and embryo survival rates were similar $(P>0 \cdot 10)$ for unilateral and bilateral twin embryo distributions up to Day 53 of gestation (Table 1). Embryo survival rates through to term are presented in Table 2 for the remaining heifers that were diagnosed as pregnant at 45-50 days from insemination. Calving, twinning and embryo survival rates were similar $(P>0 \cdot 10)$ for the unilateral and bilateral twin embryo distributions. The incidence of pregnancy loss between Day $45-50$ and full term was $15 \cdot 1 \%$ overall and was not affected by the twin-embryo distribution. Most of the pregnancy loss had occurred by Day 150 but with no indication of whether the losses were of singles or twins. Between Day 150 and term one heifer aborted twin fetuses in each group.

Table 1. Effect of a unilateral or bilateral twinembryo distribution on pregnancy rate and embryonic survival up to Day 53 of gestation in heifers

\begin{tabular}{|c|c|c|}
\hline & \multicolumn{2}{|c|}{ Embryo distribution } \\
\hline & Unilateral & Bilateral \\
\hline No. of recipients & 66 & 57 \\
\hline $\begin{array}{l}\text { No. pregnant at Days } \\
\quad 45-50(\%)\end{array}$ & $50(76)$ & $43(75)$ \\
\hline $\begin{array}{l}\text { No. pregnant, killed at } \\
\text { Day } 53\end{array}$ & 20 & 20 \\
\hline $\begin{array}{l}\text { No. with twin embryos } \\
(\%)\end{array}$ & $11(55)$ & $12(60)$ \\
\hline $\begin{array}{l}\text { Embryo survival in } \\
\text { pregnant recipients } \\
(\%)^{*}\end{array}$ & $31(78)$ & $32(80)$ \\
\hline
\end{tabular}

*Assuming $100 \%$ fertilization in both groups.

\section{Experiment 2}

In the parous cows, pregnancy, calving, twinning and embryo survival rates to full term were similar $(P>0 \cdot 10)$ for the unilateral and bilateral twin embryo distribution groups (see Table 3 ). 
Table 2. Effect of a unilateral or bilateral twinembryo distribution on fetal survival to term in heifers diagnosed pregnant at Days $45-50$

\begin{tabular}{llc}
\hline & \multicolumn{2}{c}{ Embryo distribution } \\
\cline { 2 - 3 } & Unilateral & Bilateral \\
\hline $\begin{array}{l}\text { No. of recipients pregnant } \\
\text { at Days 45-50 }\end{array}$ & 30 & 23 \\
$\begin{array}{l}\text { No. of recipients pregnant } \\
\text { at } 150 \text { days (\%) }\end{array}$ & $26(87)$ & $21(91)$ \\
$\begin{array}{l}\text { No. of recipients calved } \\
(\%)^{*}\end{array}$ & $25(83)$ & $20(87)$ \\
$\begin{array}{l}\text { No. of sets of twins born } \\
(\%)\end{array}$ & $15(60)$ & $12(60)$ \\
$\begin{array}{l}\text { No. of singles born (\%) } \\
\text { Embryo survival in calved } \\
\text { recipients (\%) }\end{array}$ & $10(40)$ & $8(40)$ \\
$\begin{array}{l}\text { Embryo survival overall } \dagger \\
\text { Emb }\end{array}$ & $40(80)$ & $32(80)$ \\
* One set of twins aborted from each group. \\
tCalculated from the combined slaughter and calving \\
data.
\end{tabular}

The overall incidence of pregnancy loss between Day 50 and term was $8 \%$ and was unaffected by the twin-embryo distribution.

\section{Survival rate of native and transferred embryos}

The use of different breed sires allowed distinction between native and transferred calves born and the data on embryo survival are summarized from both experiments in Table 4 . The overall survival rates of native and transferred embryos were similar $(P>0 \cdot 10)$. The survival rate of the native embryos and transferred embryos and both combined were similar $(P>0.05)$ for Exps 1 and 2. There was no interaction between embryo distribution and experiment for native, transferred or overall embryo survival rate $(P>0.05)$. Therefore, the data from both experiments were combined. In animals that calved there was a higher survival rate of the transferred embryos $(P<0.05)$ in the unilateral groups and of the native embryos $(P<0.05)$ in the bilateral group. More 'transfer' single calves $(P<0.05)$ were born from the unilateral than the bilateral group and more native singles $(P<0.05)$ from the bilateral group.

\section{Discussion}

The results presented show that the confinement of two embryos within the ipsilateral uterine horn did not increase the rate of embryonic or fetal mortality compared with a bilateral distribution. The transfer of the second embryo to an already inseminated recipient cow is therefore an effective means of inducing twin pregnancy, and the site of transfer (ipsilateral or contralateral) will not affect the twin-calving rate.

In Exp. 1, the pregnancy rates of $76 \%$ and $75 \%$, for unilateral and bilateral twin embryo distributions respectively, at 45-50 days from insemination in the heifers are in agreement with the rates of $73 \%$ and $72 \%$ reported by Rowson et al. (1971) for similar distributions. Pregnancy rates within the range $71-76 \%$ at $40-50$ days after bilateral embryo transfers have also been reported (Sreenan et al., 1975; Anderson et al., 1978). In Exp. 2 the calving rate of $63 \%$ in mature cows for 
Table 3. Effect of a unilateral or bilateral twinembryo distribution on embryo survival rate to term in parous cows

\begin{tabular}{lcc}
\hline & \multicolumn{2}{c}{$\begin{array}{c}\text { Twin embryo } \\
\text { distribution }\end{array}$} \\
\cline { 2 - 3 } & Unilateral & Bilateral \\
\hline $\begin{array}{l}\text { No. of cows } \\
\text { No. pregnant at Day 50 } \\
(\%)\end{array}$ & 49 & 46 \\
$\begin{array}{l}\text { No. pregnant at Day 150 } \\
\text { No. calved (\%) }\end{array}$ & $31(63)$ & $33(72)$ \\
$\begin{array}{l}\text { No. of sets of twins born } \\
(\%)\end{array}$ & $30(61)$ & $29(63)$ \\
$\begin{array}{l}\text { No. of singles born (\%) } \\
\text { Embryo survival in calved } \\
\text { recipients (\%) }\end{array}$ & $10(33)$ & $11(38)$ \\
$\begin{array}{l}\text { Embryo survival overall } \\
(\%)\end{array}$ & $40(67)$ & $18(62)$ \\
\hline
\end{tabular}

Table 4. The effect of a unilateral or bilateral twin-embryo distribution on the survival of native and transferred embryos

\begin{tabular}{|c|c|c|c|c|}
\hline & \multicolumn{4}{|c|}{ Twin embryo distribution } \\
\hline & \multicolumn{2}{|c|}{ Unilateral } & \multicolumn{2}{|c|}{ Bilateral } \\
\hline & Exp. 1 & Exp. 2 & Exp. 1 & Exp. 2 \\
\hline Total calves born & 40 & 40 & 32 & 40 \\
\hline Native embryo survival (\%) & $19(48)$ & $25(63)$ & $19(59)$ & $27(68)$ \\
\hline $\begin{array}{l}\text { Transferred embryo } \\
\text { survival }(\%)\end{array}$ & $21(52)$ & $15(40)$ & $13(41)$ & $13(33)$ \\
\hline Single calves born & 10 & 20 & 8 & 18 \\
\hline $\begin{array}{l}\text { Native single calves } \\
\text { surviving }(\%)\end{array}$ & $4(40)$ & $15(75)$ & $7(88)$ & $16(89)$ \\
\hline $\begin{array}{l}\text { Transferred single calves } \\
\text { surviving }(\%)\end{array}$ & $6(60)$ & $5(25)$ & $1(12)$ & $2(10)$ \\
\hline
\end{tabular}

the bilateral embryo distribution is in agreement with a previously published rate of $58 \%$ from this laboratory (Sreenan et al., 1981) and a rate of $57 \%$ published by Renard et al. (1979). There are no comparable reports of calving data for unilateral twin-embryo distributions.

The overall pregnancy loss between about Day 50 and term was higher for the gravid heifers $(15 \cdot 1 \%)$ than for the parous cows $(8 \%)$ but was unaffected by the embryo distribution. The losses recorded for both parity groups are consistent with published estimates (see review by Sreenan $\&$ Diskin, 1986).

There was no difference in twin-pregnancy, twin-calving, or overall embryonic mortality rate between the unilateral and bilateral embryo distributions within Exps 1 and 2. This contrasts with the conclusions drawn by Rowson et al. (1971) who used embryo transfer to achieve similar embryo distributions. These authors recorded viable twinning rates of $40 \%(\mathrm{~N}=10)$ and $73 \%(\mathrm{~N}=11)$ and embryo survival rates of $65 \%(\mathrm{~N}=20)$ and $86 \%(\mathrm{~N}=22)$ in pregnant recipient heifers with 
unilateral and bilateral embryo distributions respectively. While Rowson et al. (1971) concluded that embryo mortality was higher in the unilateral group, the number of observations was too limited to indicate a statistically significant difference. Following the surgical transfer of two embryos to the tip of the ipsilateral uterine horn, Newcomb et al. (1980) reported twin-pregnancy and embryo-survival rates of $56 \%$ and $78 \%$, respectively, in a group of 16 pregnant recipient heifers. In a separate group of 18 pregnant recipients within the same study, these authors reported twin-pregnancy and embryo-survival rates of $61 \%$ and $73 \%$ respectively following a bilateral embryo distribution. These data are consistent with the results of the present Exps 1 and 2 .

While the overall embryo survival rate was unaffected by the embryo distribution, there was a tendency within each of the two experiments for the survival rate of the native embryo to be reduced in the unilateral twin embryo distribution. When the data from both experiments are combined for all recipients the estimated embryo survival rate of native embryos in a bilateral distribution is $59 \%(46 / 78)$ compared with $49 \%(44 / 89)$ in a unilateral distribution. This trend is also evident in pregnant recipients. When the data from both experiments are combined for pregnant recipients, the survival rate of native embryos in pregnant recipients is reduced from $94 \%$ $(46 / 49)$ for a bilateral distribution to $80 \%(44 / 55)$ for a unilateral distribution $(P<0.05)$. This would suggest that the transferred embryo adversely affected the survival rate of the native embryo. Because of the local unilateral relationship between the corpus luteum, its adjacent uterine horn and the embryo (Del Campo et al., 1977), the presence of two embryos within the ipsilateral uterine horn should significantly increase the chances of establishing a pregnancy compared with one embryo located in each uterine horn, provided that each embryo acts independently of the other. Based on an expected embryo-survival rate to term of about $60 \%$ following spontaneous ovulation and insemination (Sreenan \& Diskin, 1986) and on an expected embryo-survival rate to term also of about $60 \%$ following single embryo transfer (Greve \& Del Campo, 1986), the calving rate for a unilateral twin embryo distribution derived in this manner should be $84 \%$. However, the observed calving rate for the unilateral group in Exp. 2 is only $61 \%$ and the estimated calving rate for the unilateral group in Exp. 1 is $64 \%$. Therefore, while the confinement of two embryos within the ipsilateral uterine horn resulted in similar calving, twinning and overall embryo-survival rates as for a bilateral distribution, these rates are clearly lower than would be expected if each embryo acted independently of the other. It is unlikely that the transfer procedure adversely affected the survival rate of the native embryos as it has been shown that the fertility of mated heifers was unaffected by sham embryo-transfer procedures carried out to the contralateral (Brand \& Drost, 1977) or ipsilateral (Seidel et al., 1975) uterine horns.

The higher survival rate of native embryos in this report with bilateral distribution is in agreement with previous published reports from this laboratory. After bilateral surgical transfers, embryo survival rates of $60 \%$ and $31 \%$ were reported for the ipsilateral and contralateral uterine horns, respectively (Sreenan et al., 1975). Following contralateral embryo transfers to previously inseminated recipients, embryo survival rates of $60 \%$ and $44 \%$ and again $50 \%$ and $32 \%$ were reported for the native and transferred embryos, respectively (Sreenan \& McDonagh, 1979; Sreenan et al., 1981). Of the single calves born in this study a higher proportion was from the transferred embryos in the unilateral distribution groups compared with the bilateral groups. The very low proportion of single calves that derived from the transferred embryos in the bilateral distribution groups is consistent with the published literature. Single embryo transfers to the contralateral horn, without a viable embryo in the ipsilateral horn, have consistently resulted in a high rate of embryonic mortality because of failure of the luteotrophic and antiluteolytic signals from the embryo to reach the corpus luteum (see review by Seidel, 1980).

Several abattoir surveys (Erdheim, 1942; Scanlon et al., 1974; Al-Dahash \& David, 1977) on the distribution of twin ovulations in twin-pregnant cows have indicated a higher proportion of bilateral than unilateral twin pregnancies. Reviewing these data, Hanrahan (1983) estimated that the probability of embryo loss was increased by $22 \%$ for unilateral twin ovulations compared with bilateral or single ovulations. Data from Morris et al. (1988) similarly suggest a lower embryo 
survival rate after unilateral twin ovulations than after bilateral twin ovulations in spontaneously ovulating cows. In that study twin-calving rates of $11 \%$ and $38 \%$ were recorded following unilateral and bilateral double ovulations, respectively. These data contrast with the present results and also with those of Echternkamp \& Gregory (1987), who found that pregnancy and embryosurvival rates were similar for cows with single and multiple ovulations irrespective of whether these occurred unilaterally or bilaterally. They recorded pregnancy rates of $81.9 \%$ and $75.8 \%$ and twinning rates of $45.5 \%$ and $58.6 \%$ following bilateral and unilateral multiple ovulation, respectively.

While the published data on embryo-survival rates in spontaneously twin-ovulating cows are confounded with fertilization failure, the results of our experiments demonstrate that confinement of two embryos in one uterine horn on or after Day 7 does not depress pregnancy, twinning or overall embryo-survival rates to term. Further studies are required to determine fertilization rate and embryo survival accurately in spontaneously uni- and bilateral twin-ovulating cows.

We thank Mr T. McDonagh, Mr W. Connolly and Mr G. Morris for technical support; and $\mathrm{Mr}$ G. Burke and Mr B. O'Brien for care of the animals. The work was supported in part by the Commission of the European Communities.

\section{References}

Al-Dahash, S.Y.A. \& David, J.S.E. (1977) The incidence of ovarian activity, pregnancy and bovine genital abnormalities shown by an abattoir survey. Vet. Rec. 101, 296-299.

Anderson, G.B., Cupps, P.T., Drost, M., Horton, M.B. \& Wright, R.W., Jr (1978) Induction of twinning in beef heifers by bilateral embryo transfer. J. Anim. Sci. 46, $449-452$.

Brand, A. \& Drost, M. (1977) Embryo transfer by nonsurgical methods. In Embryo Transfer in Farm Animals, pp. 31-34, Ed. K. J. Betteridge. Can. Dept. Agric. Monograph No. 16.

Del Campo, M.R., Rowe R.F., French, L.R. \& Ginther, O.J. (I977) Unilateral relationship of embryos and the corpus luteum in cattle. Biol. Reprod. 16, 580-585.

Dickerson, G.E. (1983) Potential genetic improvements in the efficiency of beef production. Proc. Int. Symposium on Beef Production, Kyoto, Japan, pp. 85-119.

Diskin, M.G. \& Hickey, B.C. (1987) The impact of twincalving on beef output and financial returns. Ir. Grassid. \& Anim. Prod. Assoc. J. 21, 153, abstr.

Echternkamp, S.E. \& Gregory, K.E. (1987) Factors affecting ovulation rate and twinning rate in cattle selected for twins. J. Anim. Sci. 65 (Suppl. 1), 205, abstr.

Elsden, R.P., Nelson, L.D. \& Seidel, G.E. (1978) Superovulating cows with follicle stimulating hormone and pregnant mare's serum gonadotrophin. Theriogenology $\mathbf{9}$, $17-26$.

Erdheim, M. (1942) The incidence of right and left horn pregnancies in dairy and beef cattle. J. Am. vet. med. Assoc. 100, 343-344.

Gordon, I., Williams, G. \& Edwards, J. (1962) The use of serum gonadotrophin (P.M.S.) in the induction of twin-pregnancy in the cow. J. agric. Sci., Camb. 59, $143-198$.

Greve, T. \& Del Campo, M. (1986) Embryo loss following transfer in cattle and swine. In Embryonic Mortality in Farm Animals, pp. 179-194. Eds J. M. Screenan \& M. G. Diskin. Martinus Nijhoff, The Hague.

Hanrahan, J.P. (1983) The inter-ovarian distribution of twin ovulations and embryo survival in the bovine. Theriogenology 20, 3-11.

Mauleon, P., Chupin, D., Pelot, J. \& Aguer, D. (1978) Modifying factors of fertility after different oestrous control treatments in beef cattle. In Control of Reproduction in the Cow, pp. 281-291. Ed. J. M. Sreenan. C.E.C., Luxembourg.

Morris, C.A. (1984) A review of the genetics and reproductive physiology of dizygotic twinning in cattle. Anim. Breed Abstr. 52, 803-819.

Morris, C.A. \& Day, A.M. (1986) Potential for genetic twinning in cattle. Proc. 3rd Wld Congr. on Genetics Applied to Livestock Production, Lincoln, NE II, 14-29.

Morris, C.A., Day, A.M. \& Macmillan, K.L. (1988) Studies of ovulation rate, embryo survival and calving rate in a twin breeding experiment. Proc. 11th Int. Congr. Anim. Reprod. \& A.I., Dublin 2, 109, abstr.

Mulvehill, P. \& Sreenan, J.M. (1978) Oestrous cycle control and fertility in beef cattle following short-term progestogen treatment. In Control of Reproduction in the Cow, pp. 486-510. Ed. J. M. Sreenan. Martinus Nijhoff, The Hague.

Newcomb, R., Christie, W.B. \& Rowson, L.E.A. (1980) Fetal survival rate after the surgical transfer of two embryos. J. Reprod. Fert. 59, 31-36.

Piper, L.R. \& Bindon, B.M. (1979) Selection for increased cow fecundity. Proc. N.Z. Soc. Anim. Prod. 39, 224-232.

Renard, J.P., Oxil, J.P. \& Heyman, Y. (1979) The use of embryo transfer in the field for increased calf crops in breed and dairy cattle. Anim. Reprod. Sci. 2, 353-361.

Rowson, L.E.A., Lawson, R.A.S. \& Moor, R.M. (1971) Production of twins in cattle by egg transfer. $J$. Reprod. Fert. 25, 261-268.

Scanlon, P.F. (1972) Frequency of transuterine migration of embryos in ewes and cows. J. Anim. Sci. 34, 791-794. 
Scanlon, P.F., Gordon, I. \& Sreenan, J. (1974) Multiple ovulations, multiple pregnancies and multiple births in Irish cattle. J. Ir. Dept. Agric. Fish. 70, 1-18.

Seidel, G.E. (1980) Critical review of embryo transfer procedures with cattle. In Fertilization and Embryonic Development in Vitro, pp. 323-353. Eds L. Mastroinanni Jr \& J. D. Biggers. Plenum Press, New York.

Seidel, G.E., Bowen, J.M. \& Homan, N.E. (1975) Fertility of heifers with sham embryo transfer through the cervix. Vet Rec. 97, 307-308.

Sreenan, J.M. (1977) Embryo transfer for the induction of twinning in cattle. In Embryo Transfer in Farm Animals, pp. 62-66. Ed. K. J. Betteridge. Can. Dept. Agric. Monograph 16.

Sreenan, J.M. (1984) Steroid immunisation in cows: Potential for increasing ovulation and twinning rates. Proc. 10th Int. Congr. Anim. Reprod. \& A.I., Urbana 4, VIII-22.

Sreenan, J.M. \& Beehan, D. (1976) Effect of site of transfer on pregnancy and twinning rates following bilateral egg transfer in the cow. J. Reprod. Fert. 48, 223-224.

Sreenan, J.M. \& Diskin, M.G. (1982) Current efficiency of embryo transfer technology and its role in cattle breeding. Ir. vet. J. 36, 138-144.

Sreenan, J.M. \& Diskin M.G. (1986) The extent and timing of embryo loss in cattle. In Embryonic Mor- tality in Farm Animals, pp. 1-11. Eds J. M. Sreenan \& M. G. Diskin. Martinus Nijhoff, The Hague.

Sreenan, J.M. \& McDonagh, T. (1979) Comparison of the embryo survival rate in heifers following artificial insemination, non-surgical blastocyst transfer or both. J. Reprod. Fert. 56, 281-284.

Sreenan, J.M., Beehan, D. \& Mulvehill, P. (1975) Egg transfer in the cow: factors affecting pregnancy and twinning rates following bilateral transfers. $J$. Reprod. Fert. 45, 77-85.

Sreenan, J.M., Diskin, M.G. \& McDonagh, T. (1981) Induction of twin-calving by non-surgical embryo transfer: a field trial. Vet. Rec. 109, 77-80.

Steel, R.G.D. \& Torrie, J.H. (1980) Principles and Procedures of Statistics: A Biometrical Approach, 2nd edn. McGraw-Hill Book Co., New York.

Webb, R., Land, R.B., Pathiraja, N. \& Morris, B.A. (1984) Passive immunisation against steroids in the female. In Immunological Aspects of Reproduction in Mammals, pp. 475-499. Ed. D. B. Crighton. Butterworths, London.

Wise, T.H. \& Schanbacher, B.D. (1983) Reproductive effects of immunizing heifers against androstenedione and oestradiol-17ß. J. Reprod. Fert. 69, 605-612.

Received 7 March 1989 